Original Article

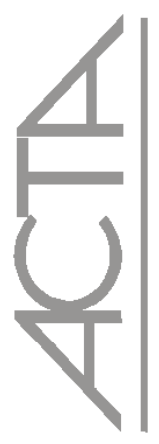

\title{
The role of fathers in the postpartum period: experiences with skin to skin method*
}

\author{
O papel do pai no periodo pós-parto: experiências com o método pele a pele \\ Elpapel del padre en el periodo del postparto: experiencias con el método piel a piel
}

\author{
Joaquín Jesús Blanca Gutiérrez ${ }^{1}$, María del Rosario Ábalos Pérez², Maria Victoria \\ Montes Aguilera², Soledad González Moreno ${ }^{3}$
}

\begin{abstract}
Objective: This study aimed at investigating the significance of the skin-to-skin contact method with fathers, looking at their own experiences with their newborns. Methods: The information was collected through in-depth interviews with 14 fathers who had used the skin-to-skin contact method with their newborns, after a cesarean delivery. The technique utilized for data analysis was the qualitative method of content analysis. Results: Four principal themes emerged from the data: the preparation for the skin-to-skin method, the experiences of the fathers, the father's role, and effects of the method on the baby. Conclusions: The investigations performed highlighted the importance of the involvement of health professionals in the use of this method, which leads to a series of positive results for the organization related to satisfaction. We conclude that the skin-to-skin method is a simple technique, recommended for positive results for fathers and their babies.
\end{abstract}

Keywords: Infant, newborn; Cesarean section; Parent-child relations; qualitative research; Kangaroo-mother care method

\section{RESUMO}

Objetivo: Este estudo tem como objetivo investigar o significado do método "pele a pele" com pais, olhando para as suas próprias experiências com seus recém-nascidos. Métodos: A informação foi coletada a través de "entrevistas em profundidade" em 14 pais que tinham usado o método de "pele a pele", com seus recém-nascidos após um parto por cesariana. A técnica utilizada no análise dos dados foi o método qualitativo de "análise de conteúdo". Resultados: Quatro temas principais emergiram a partir dos dados: a preparação para o método "pele a pele", as experiências dos pais, o papel do pai e os efeitos do método no bebê. Conclusões: As investigações feitas destacam a importância do envolvimento dos profissionais da saúde na utilização deste método, o qual leva a uma série de resultados positivos para a organização relacionados com a satisfação. Concluímos que o método de "pele a pele" é uma técnica simples e recomendada com resultados positivos também para os pais e os seus bebês.

Descritores: Recém-nascido; Cesárea; Relações pai-filho; Pesquisa qualitativa; Método mãe-canguru

\section{RESUMEN}

Objetivo: En este estudio se tuvo como objetivo investigar el significado del método "piel a piel" con padres, mirando hacia sus propias experiencias con sus recién nacidos. Métodos: La información fue recolectada por medio de "entrevistas en profundidad" realizada a 14 padres que habían usado el método de "piel a piel”, con sus recién nacidos después de un parto por cesárea. La técnica utilizada en el análisis de los datos fue el método cualitativo de "análisis de contenido". Resultados: Emergieron cuatro temas principales a partir de los datos: la preparación para el método "piel a piel”, las experiencias de los padres, el papel del padre los efectos del método en el bebé. Conclusiones: Las investigaciones realizadas destacan la importancia del involucramiento de los profesionales de la salud en la utilización de este método, lo cual lleva a una serie de resultados positivos para la organización relacionados con la satisfacción. Concluimos que el método de "piel a piel" es una técnica simple y recomendada con resultados positivos también para los padres y sus bebés.

Descriptores: Recién nacido; Cesárea; Relaciones padres-hijo; Investigación cualitativa; Método madre-canguro

\footnotetext{
* Study carried out at Hospital "Infanta Margarita", Cabra, Spain.

${ }^{1}$ Doctor of Gerontology, University of Jaén (Spain). Chief of Formation and Investigation of the Hospital "Infanta Margarita", Cabra, Spain.

${ }^{2}$ Obstetric Service. Hospital "Infanta Margarita", Cabra, Spain.

${ }^{3}$ Chief of nurses in Obstetric Service. Hospital "Infanta Margarita", Cabra, Spain.
} 


\section{INTRODUCTION}

Skin-to-skin contact between a mother and the newborn is achieved by putting the infant face down on the mother's breast as soon as possible after birth. This technique is based on a series of innate behaviours in mammals, as we need maternal contact to be maintained after birth in order for behaviours which lead to suckling and survival to be established ${ }^{(1)}$.

There is quite solid experimental evidence about the benefits of this technique on a series of health issues for infant and mother: it contributes to attachment; helps the infant find the nipple through smell; helps early recognition of the mother through smell; helps maintain temperature; leads to early rebalancing of blood-sugar levels ; reduces stress and also crying in the newborn; increases chances of successful first attempt at breastfeeding; increases the mother's confidence; reduces the mother's anxiety; helps her take on her new role; increases feelings of satisfaction around the birthing process for the mother; raises self-esteem and the mother's ability to care for the infant; and it helps develop bonding behaviours. ${ }^{(2)}$

When birth is by caesarean section, whether elected or emergency, the mother and newborn are routinely separated while the mother goes through post-anaesthetic recovery. In these cases, there have been experiences where the skin-to-skin method has been established between the newborn and the father. There is also research which has demonstrated the positive effects, both physiological and behavioural, of using this method with the father:

- Christensson ${ }^{(3)}$ studied temperature changes in a group of healthy neonates born after elective caesarean. They were randomly placed in three different environments: a cot, an incubator and in skin-to-skin contact with the father. They found a greater rise in temperature in those placed with the father, compared to those placed in a cot. There were no significant differences between those placed with the father and those placed in an incubator. However, after 24 hours the increase in temperature in the skin-to-skin group was significantly higher than even the incubator group. In the group which was placed with the father, there was a significant increase in blood-sugar level, compared to the other two groups.

- Sullivan ${ }^{(4)}$ demonstrated that the earlier contact is established between parents and premature neonates, the earlier the parents demonstrate warmth and love towards their infants.

- Erlandsson et $\mathrm{a}^{(5)}$ placed neonates in two groups: one which had skin-to-skin contact with the father, and another in which the neonates were simply kept near their fathers. They found that the neonates in the first group cried less and were calm and asleep within 60 minutes (as opposed to 110 minutes for those in cots).
Several studies have addressed the issue of the experiences of the mother in relation to the "kangaroo" method, but the justification of our current study is based on there is hardly any scientific literature about the question of the experiences of fathers regarding to this technique. Therefore, this study aims to investigate the significance of the skin-to-skin method with fathers, looking at their own experiences with their neonates. The research question to which we try to answer is: How are the experiences of fathers in relation to the performance of the method "skin to skin" with his newborn son?

\section{METHODS}

We use Husserl's eidetic reduction as our theoretical framework ${ }^{(\sigma)}$. Eidetic reduction is an investigative method which seeks to identify the basic structures which make up any given human interaction. Research based on eidetic phenomenology attempts to describe the significance of an experience from the point of view of those who have had the experience; in other words, it starts from the experiential evidence of those who have lived the experience and deemed it meaningful ${ }^{(6,7)}$.

We have used a systematic inductive approach, based on qualitative research tools and methods.

The design we have used is qualitative, description-based research, which "faithfully represents the life of the social agents involved. These are studies with a low level of interpretation, and an analysis which is implicit for organising the discourse. As these are first-hand narratives, the intention is to offer readers an opportunity to reflect on the reality described so that they may come to their own conclusions." (8)

This study took place at the Hospital Infanta Margarita (Cabra, Spain). This is a regional hospital which offers specialised health services to a population of approximately 150,000.

The selection of participants followed an intentional and theoretical sampling: we invited people who were considered more relevant to the study to participate, in this case, fathers who have made the technique of skin contact with their newborns, which have been lighted from a cesarean section. It has sought to obtain variety of aspects such as age, educational level and type of work. As data analysis progressed, we widened the number of interviewees in order to gain as wide a perspective as possible in each of the categories/themes which emerged from analysis of information ${ }^{(9,10)}$.

Data was collected using "in depth interviews". These are used to establish what is important for those who are being interviewed: what they have found to be significant, their perspectives and definitions. ${ }^{(9)}$

The interviews took place in a room placed in the gynaecology ward used for talking to and providing 
information for patients and family members. The testimonies of the participants were recorded digitally and later transcribed verbatim.

In our first meetings, we just requested our participants to relate us their experience with the performance of the skin to skin method with their child. Because while we were doing the first interviews we performed simultaneous analysis of the data they provided, finally, the meetings were structuring by a interview script that was defined by the various categories and subcategories that emerged in treating the information, according to the inductive development of the methodology of qualitative research, but without losing the character of "open interview" of the dialogues.

These deep interviews were carried out at least 24 hours from the birth. When interviews stopped yielding new information for each of the identified categories/ themes under study, no further interviewees were sought: this was the criteria for theoretical saturation ${ }^{(9,10)}$.

As we have indicated, data analysis took place concurrently with the interview period. The technique used was "content analysis" (11): a combination of methods and analytical procedures which emphasises the meaning of the text. It identifies two levels of complexity, the descriptive and the inferential, and may use both qualitative and quantitative methods of analysis ${ }^{(12)}$. Specifically, we used the practical method put forward by Amezcua and Hueso (13), which is based on the previously cited work of Taylor and Bodgan ${ }^{(9)}$, and suggests the following steps: preparation of data, identification of themes, codification, interpretation, relativisation, determination of rigour.

We have used the following strategies in order to address the area of rigour in our study:

- Triangulation ${ }^{(9,13)}$, which involves using different sources of data in the same study. For this, we used a $\log$ which the gynaecology ward has and in which fathers and mothers record their experiences of childbirth. We found entries in the log where fathers who had used the skin-to-skin method had written about their experiences.

- We made fragments of the results we had obtained in our research available to some of our participants, in order to check whether they really felt represented in the way the data was being analysed ${ }^{(9,13)}$.

- We have used Consolidated Criteria for Reporting Qualitative Research (COREQ) as a support tool. This consists of a list of 32 verification items with regard to the research team, the research design and analysis of the data in relation to qualitative research methods ${ }^{(14)}$.

With regard to ethical issues, we must inform that parents voluntarily participated in the interviews, who signed a communicative contract document as informed consent, and that the researchers ensured privacy and confidentiality of the participants at any time of this study. When participants have cited names of hospital professionals, they have been replaced by fictitious names. The research project was approved by the direction of the Clinical Management Unit of Obstetrics and Gynecology in Hospital "Infanta Margarita".

\section{RESULTS}

A total of 14 fathers, aged between 24 and 48, took part in this study. With regard to work, have been included as informants two masons, three carpenters, one painter, one truck driver, one businessman of wine, one engineer, one tattoo maker, one teacher, two trader and one waiter. Regarding the educational level of participants, five had primary studies, five had secondary studies and four had university education.

\section{Preparation}

Once the decision to carry out a caesarean delivery has been taken, the father and other family members wait in the waiting room. The offer of using the skin-to-skin method would be made to the father by a member of the nursing team (nurses and midwives), as a suggestion, and their reaction was fairly keen. Nevertheless, there were no cases where a father himself suggested the skin-toskin method; this was always in response to a suggestion from the nursing team.

S9: "When we were here the midwife and nurse suggested it. They told me about the method and I said yes, I wanted to try it".

S10: "The nurses offered me the baby and asked if I wanted to hold him or leave him in the cot".

What is proposed draws people's attention; it is something new when compared with the more traditional custom of placing the baby in a cot, waiting for the mother to get better and leaving the father as a mere non-participative spectator

S3: "What happened was, or what they offered me was whether I wanted to hold the baby or put him in the cot."

On occasion, the physiological state of the baby prevented this being an option, either because the baby needed to be placed in an incubator or because phototherapy was needed. In these circumstances, the father is again put in the position of non-participative spectator. Where the father has already had children, this opportunity of using the skin-to-skin method is seen as a lucky opportunity, a positive move, in comparison with previous births where this was not a possibility.

S14: "Then the midwife asked me if I wanted to try the 'skinto-skin' method on me, and I said yes, because my other girl who was born 4 years ago well I wasn't lucky enough to be able to do $i$, because they just put her in a cot under a light, for 2 hours, and all I could do was look at her."

Before starting with the skin contact, either the father or a member of the hospital team briefly shows the baby to the other family members (brothers and sisters, 
grandparents, uncles and aunts, cousins... etc) who have been with them in hospital during the labour and birth.

S9: "They showed him to my family and they said that I'd stay with him while my wife was coming round."

S14: "After my mother and mother-in-law had seen her, they went out and asked us to go into another room. "

The father and baby are given a private, quiet place, such as the room where they will spend the rest of their time in hospital. This is a single room equipped for the use of the couple and baby to live in together while they are in the hospital.

S8: "They took us to a room and the light was on over the cot, in case I wanted to leave the baby there."

\section{The fathers'experiences}

The fathers describe the first few moments as very emotional, with real impact. At this time, they are more nervous and tense; they even feel frightened of what they are going through, especially if the baby is their first. This is not fear of the skin-to-skin method, but rather of the new stage in their lives that they are entering:

S4: "When the nurse came out with the baby, I was surprised, really. I didn't know whether to hold him or not. I didn't know what to do."

S13: "They gave me the baby - I think it was the midwife who gave him to me. Well, it's my first baby and to be honest the first thing I felt was frightened."

For all those interviewed, the experiences have been very positive. We have a number of comments and feelings expressing how much they have valued the experience, their hopes, satisfactions, pride, happiness, surprise. They speak of how emotional they felt, that this was an experience they couldn't put into words, how marvellous it was...

S6: "It was a buge... and satisfaction for me. Words can't describe what you feel in those moments, having your baby so close."

S7: "For me, being able to be with my baby for the first few hours was an experience beyond words. I don't know how to explain it, it's the most important thing that's ever happened to me, being able to hold my baby in my arms."

The feelings and sentiments were felt very intensely, and many fathers wept with emotion:

S8: "When the midwife passed me the baby in the corridor, I cried all the way down the corridor. "

S9: "W hen you see your baby it's really emotional and you cry big tears."

Fathers who have had other children compare their experiences with previous births in which they did not use the skin-to-skin method; and they find that this method was far more gratifying. In various testimonies they strongly recommend this experience for other people who might be able to take part in it:

S14: "If I compare my experiences with my daughter's birth, I have to say that this method was far better."
S12: 'My friends and family who've had children haven't done this, or at least they haven't said anything to me. I would recommend this to everyone, and if I could do it again I would."

Using this method fosters the development of feelings of gratitude towards the hospital staff. It gives rise to more open relationships between fathers and health professionals, which leads to a stronger appreciation of the work done by them:

S9: "When we were here, Ana, the midwife, and Joaquin made the suggestion. They both told me about the method and I said that I wanted to try it. They called me when they came through the door and told me."

S2: "I value the experience more, and the staff were more attentive."

The baby is seen as a human being with whom we can interact from the very first moments of life. The fathers felt that this close contact was benefitting their babies:

S8: "When we got to the room I started talking to her [the baby] and the midwife told me to hold her close because she'd recognise my heartbeat."

S13: "And I don't know if it was because of the calmness which he passed on to me, but I fell asleep too."

S14: "So I held her close and well I think that settled her."

\section{The father's role}

For the majority of these participants, using this method was an introduction, a first interaction and first step toward taking on the role of father, especially for those who were having their first child:

S3: "It's a way of coming nearer to and taking on your new role. In my opinion, as I've never experienced this before."

S5: "T've never had such close contact with babies."

Other fathers had developed their first interactions with the baby throughout the pregnancy, and so for them this method constituted a more physical extension of the communication they had already been developing with the baby for a number of months.

S8: "We spoke to the baby a lot while she was in the womb. Sometimes, we could see her little hand. It was amazing, saying her name and telling her that daddy was here, and it calmed her... it's better than seeing her, feeling her breathing, she would move and you were nearer and could feel her better... I... if you've had contact with her during the pregnancy, interacting with your baby... I would hum her songs which she'd maybe heard when she was in the car, tried to remind her of things I'd done."

Some of the fathers thought of their role in this as one of substituting for the mother, whose rightful place it was, but who could not use the method herself because she was still coming round from the anaesthetic after the caesarean section.

S3: "When you try it and you see it's $O K$ and works well, that we're all equal, so to speak, so if the mother can't do it... well here we are." 
S5: "The truth is that it's best for the baby to be with the mother at this time, but if the mother isn't available, then it's best to be with the father."

S7: "Without any doubt, as the mother can't do it I recommend being with your baby."

These differences about the different roles of mothers and fathers are attributed to the strong physical bond between mothers and babies which develops during pregnancy. The skin-to-skin method is the first real physical contact between fathers and their babies and they draw comparison between the two experiences: pregnancy with the mother and skin-to-skin with them:

S9: "The first thing I realised was how my wife must have felt having the baby inside her, something which was taking me over. I realised how lovely it must be to carry the baby, and how uncomfortable too."

Being reunited with the mother creates a nucleus of three (mother, father and baby), separate from the other family members who have accompanied them through the time in hospital:

S6: "When my wife was able to come up to the room we were overjoyed to be altogether, the three of us, as you are."

S8: "We were finally reunited the next night, when all our visitors had gone. You do need to keep an eye on how many visitors you have."

This reunion is the culmination and desired end-point of the whole process of pregnancy and birth, so that they can start a new stage.

S14: "The reunion with my wife was very special, because during the pregnancy, when we had the scans, they had shown that the baby umbilical cord was bivascular and they had to carry out an amniocentesis test. Then they saw that she has a problem on her heart. So there was a lot of things and we didn't know how they'd all turn out, so when you see that they're all behind you, and you have the baby there all perfect for you to see, and on top of that they let you enjoy the process as I have enjoyed it..."

Effects of the skin-to-skin method on the baby

The fathers were surprised and very pleased when their babies opened their eyes:

S1: "He didn't stop opening his eyes and it looks like he can see you, that he's looking at you. Even though they say that they can't see you, that they only see shapes, but it looked like he was looking at me."

In most cases, while using the skin-to-skin method the babies would go from being nervous and crying to being calm; sometimes they would even fall asleep.

S2: 'We couldn't calm bim down, and my sister was with me too, and then they told us about the skin-to-skin method and when we tried it was great, he calmed down and I calmed down and we stayed together like that for a few hours until his mother came to us."

S5: "This is my first baby, and to be honest for me, and for bim too, he felt calmer. We were alone, just the two of us, more or less, and they didn't disturb us. To be honest the baby was really calm, and only woke up if I moved him and the rest of the time he was very calm."

This calm is broken when the baby starts to feel hungry. This is demonstrated physically with a series of actions from the baby which are described by the fathers:

S5: "I was waiting for her to come up, as he was getting hungry, searching, sucking his little hand, looking for something. He really was hungry. To be honest, as soon as his mother came up she put him to the breast straight away and he latched on very well."

S8: "What she was doing was looking to feed, and then she put her hand in her mouth and started sucking it, and then she was sucking without her hand."

S13: "The baby tried to sucke from me, which I don't think is normal."

One of the fathers in our study tried to give a physiological explanation to the need for skin-to-skin contact:

S12: "Babies listen out for the sound of a heartbeat, when they are in the womb, I think babies listen to the mother's heartbeat and then they try to find the sound of an adult heartbeat."

Other participants attribute some sort of conscious understanding to the baby, related to the baby's ability to recognise its own father:

S13: "And another thing you'd hardly believe is that the baby would know that I was his father. He looked at me and made faces at me and even seemed to want to tell me something, sucking his hand, that he was hungry, which I think is quite normal."

S14: "She would look for me, sucking her little hands, she'd open her mouth. Sometimes her eyes were closed and then suddenly she'd open them and smile."

\section{DISCUSSION}

As we have seen from the comments made by some of the participants, the involvement of hospital staff in making use of the skin-to-skin method is vital, as it is they who invite the fathers to take part. Hollanda et $\mathrm{al}^{(15)}$ carried out a descriptive study in Brazil about the perception of nurses working in a neonatal unit about using this method. They stressed the importance of the involvement of hospital mediators in establishing this method, and also the need for proper resources, in terms of staffing and infrastructure. The participants in the Brazilian Hospital expressed some mistrust before implantation technique, however, once established it, our work shows how its performance increases fathers' satisfaction in relation to the birthing process, and also promotes the development of more open relations with professionals, which can also have positive effects on job satisfaction of the staff. It would be interesting to develop future studies about the influence of regulated development of this method to the satisfaction of the professionals involved.

The literature has a number of studies along similar lines to ours, but which concentrate on the role of the mother in the skin-to-skin method; at most, they 
have included a few comments from fathers, as part of the couple:

- Furlan et $\mathrm{al}^{(16)}$ grouped the perceptions of mothers and fathers into four themes: flexibility around the presence/ absence of the mother using this method; the importance of the relationship between mother, child and family; the contribution to growth in premature babies and the development of childcaring skills.

- Martins et $\mathrm{al}^{(17)}$ studied some difficulties which may arise at a personal or even family level, and which can hinder starting the onset and development of the method, concluding that the support of hospital staff and the family was crucial.

- Another study ${ }^{(18)}$ indicate that during this period mothers pass through a "process of gradual approximation" towards the newborn. The mothers reported that using this method helped them with the learning process they were going through, to look after their child.

- Javorski et al ${ }^{(19)}$ identified a series of social behaviours developed in the mothers towards their infants through the breastfeeding process and the skin-to-skin method: breastfeeding helps the healthy development of infants, breast milk protects the infant and preserves life; it is part of motherhood and suckling a premature infant is a difficult and tiring experience.

- Caetano et $\mathrm{al}^{(20)}$ studied the changing family dynamics which arise from using this method. The fact that the experience is lived as a shared experience helps mothers and fathers come to terms with their new roles, with positive consequences for later childcare. In our study we have studied the influence of the skin-to-skin method specifically on the establishment of the role of the father.

These studies clearly show the method has positive effects on both parents in several ways: promoting their role as parents, reinforcing the initial interactions with the new baby, facilitating caring skills learning and consolidating the family as the nucleus of the baby care. Our work illustrates the consolidation of the family as a unit in a very specific time as the reunion of father-son and mother (who has finished her post-anaesthetic recovery). This moment represents for them a genuine culmination of birthing process and the beginning of a new phase for the family.

We also find in the bibliography studies with similar methodology to ours which have also looked at the specific experiences of fathers using the skin-to-skin method:

- In Lindberg et al ${ }^{(21)}$ study, similar situations to ones in this study arise, such as the 'impact' on the fathers of having to take care of their newborn. The Swedish study reports the fathers' "need to know", something which may counter the feeling of "fear" as reported by the participants in our study. In both studies, participants valued having all members of the family together (mother/father and child), and in our study there were some testimonies about the actual reuniting of the family members. In both studies the importance of participation of hospital staff was very clear.

- Ibáñez et al ${ }^{(22)}$, had similar experiences in surroundings which were geographically and culturally close to ours. Although they are still involved in both qualitative and quantitative data collection, the researchers agree with us to consider this method to be "a very satisfactory initiative for the parents who should be promoted by the staff attending the birth". They also suggest some physiological benefits for the newborn, when they state that "when the newborn is given to the mother, the onset of breastfeeding appears to be easier than in cases where the newborn has been put in an incubator." The researchers conclude that prejudice still exists about this method when used by fathers, even in health workers, and that it can seem strange to some to see a semi-naked man holding his child.

Transferability, the degree of generalization of these results, it would be most obvious limitation of this work. Our results are applicable in principle only in social and cultural contexts similar to that of our participants. While inclusion in the discussion section of research from other contexts, can contribute to the results of this study are more applied to other areas, all of them are bounded on the experiences of fathers from highly industrialized societies.

Could be raised in future studies, to address the issue of fathers in relation to childbirth and specifically with the skin to skin method, but through participants from very different cultural contexts. It would be interesting to include as informants immigrant men from non-industrialized societies, such as sub-Saharan Africa.

\section{CONCLUSION}

Nearly all the literature on the benefits of mothers and fathers using the skin-to-skin method refers to its use with premature infants. However, our study records some of the few instances of using this method with fathers, when the mother is still in post-anaesthetic recovery following a Caesarean section.

As the experiences of fathers with regard to the technique we can conclude: at first is a shocking situation evolving in a very exciting and satisfying experience, fathers are more protagonists in the process of childbirth and postpartum, initiate a close and intimate bond with the new child, more easily assume his new role as a parent-caregiver and finally instituted a family intimate nucleus at the time of reunion with the mother.

The diverse researches agree in stressing the importance of the involvement of health workers in using this method, promoting positive outcomes for the health institutions concerning satisfaction: the possible shock to fathers is countered by the information they are receiving 
by the staff, closer relationships are developed between fathers and nursing staff and in general the satisfaction of the participants regarding their experiences of the hospital and childbirth was improved.

As a result of our research and the contributions of the researches cited in the introduction and discussion, we can conclude that the skin-to-skin method is a beneficial technique with positive results for fathers and their

\section{REFERENCES}

1. Moore ER, Anderson GC, Bergman N. Early skin-to-skin contact for mothers and their healthy newborn infants. Cochrane Database Syst Rev. 2007 Jul 18;(3):CD003519. Review. Update in: Cochrane Database Syst Rev. 2012;5:CD003519.

2. Martín Casado AM, Viudes Coloma M. [Importance of early skin to skin contact with the newborn during labour]. Metas Enferm. 2010; 13 (6): 20-3. Spanish.

3. Christensson K. Fathers can effectively achieve heat conservation in healthy newborn infants. Acta Paediatr. 1996; 85 (11):1354-60.

4. Sullivan JR. Development of father-infant attachment in fathers of preterm infants. Neonatal Netw. 1999; 18(7):33-9.

5. Erlandsson K, Dsilna A, Fagerberg I, Christensson K. Skinto-skin care with the father after cesarean birth and its effect on newborn crying and prefeeding behavior. Birth. 2007; 34(2): 105-14.

6. Husserl E. Ideas relativas a una fenomenología pura y a una filosofía fenomenológica. 2a ed. Traductor Gaos J. México: Fondo de Cultura Económica; 1993. (Colección: Sección de obras de filosofía).

7. Morse JM, editor. Asuntos críticos en los métodos de investigación cualitativa. Traductor Zimmerman E. Medellín: Editorial Universidad de Antioquia; 2005. (Collección Contus).

8. Gálvez Toro A. Lectura crítica de un estudio cualitativo descriptivo. Index Enferm. 2003; 40-41:51-7.

9. Taylor SJ, Bodgan R. Introducción a los métodos cualitativos de investigación. Traductor Piatigorsky J. Barcelona: Paidós; 1987.

10. Strauss A, Corbin J. Bases de la investigación cualitativa: técnicas y procedimientos para desarrollar la teoría fundamentada. Traductor Zimmerman E. Medellín: Editorial Universidad de Antioquia; 2002. (Collección Contus).

11. Graneheim UH, Lundman B. Qualitative content analysis in nursing research: concepts, procederes and measures to achieve trustworthiness. Nurse Educ Today. 2004; 24(2):105-12. babies: there are physiological benefits, there is greater confidence in assuming a parenting role and there is the development of childcaring skills... Therefore, we can recommend the establishment of this method as a routine procedure in the hospital's maternity wards. This implementation should be accompanied with training programs that facilitate the development of skills in connection with this technique by the staff.

12. Amezcua M, Gálvez Toro A. [Different approaches to qualitative health research analysis: a critical and reflective view] Rev Esp Salud Publica. 2002; 76(5):423-36. Spanish.

13. Amezcua M, Hueso Montoro C. [How to analyse a biography story]. Arch Memoria [Internet]. 2009 [cited 2012 Jun 12]; 6 (3). Spanish. Available from: http://www.index-f.com/ memoria/6/mc30863.php

14. Tong A, Sainsbury P, Craig, J. Consolidated criteria for reporting qualitative research (COREQ): a 32-item checklist for interviews and focus groups. Int J Qual Health Care. 2007; 19 (6):349-57.

15. Parisi TC, Coelho ER, Melleiro MM. Implantation of the Kangaroo Mother Method in the perception of nurses in a university hospital . Acta Paul Enferm. 2008; 21(4): 575-80.

16. Furlan CE, Scochi CG, Furtado MC. [Perception of parents in experiencing the kangaroo mother method]. Rev Latinoam Enferm. 2003; 11(4):444-52. Portuguese.

17. Martins AJ, Santos IM. [Living in the other side of kangaroo method: the mother's experience]. Rev Eletrônica Enferm. 2008; 10(3):703-10. Portuguese.

18. Duarte ED, Sena RR. [Women's experience with the kangaroo method]. REME Rev Min Enferm. 2004; 8(4):436-41. Portuguese.

19. Javorski M, Caetano LC, Vasconcelos MG, Leite AM, Scochi CG. [Social representations on breastfeeding according to preterm infants' mothers in kangaroo care]. Rev Latinoam Enferm. 2004; 12(6):890-8. Portuguese.

20. Caetano LC, Scochi CG, Angelo M. [Living the mother-childfamily triad in the kangaroo method] Rev Latinoam Enferm. 2005; 13(4):562-8. Portuguese.

21. Lindberg B, Axelsson K, Öhrling K. The birth of premature infants: experiences from the fathers' perspective. J Neonatal Nurs. 2007; 13(4):142-9.

22. De Miguel Ibáñez MP, Casanova Aranda I, Navio Abril V, Muñoz García C, Martinez Pastor C, Formentín Torralba P, Sopale Sieriche E. Paternal "skin to skin" contact after caesarean delivery (Iniciatica "piel-con-piel" con el padre en cesáreas). Investigación \& Cuidados. 2010; 8(16):17-21. 